\title{
Anti-proliferative and cytoskeleton-disruptive effects of icariin on HepG2 cells
}

\author{
ZHI-MIN WANG ${ }^{1 *}$, NAN SONG ${ }^{2 *}$ and YAN-LING REN ${ }^{3}$ \\ ${ }^{1}$ The First Clinical Institute, Liaoning University of Traditional Chinese Medicine; ${ }^{2}$ Key Laboratory of Ministry of Education \\ for Traditional Chinese Medicine Viscera-State Theory and Applications, Liaoning University of Traditional Chinese Medicine; \\ ${ }^{3}$ School of Chinese Medical Formulae, College of Basic Medicine, Liaoning University of Traditional Chinese Medicine, \\ Shenyang, Liaoning 110847, P.R. China
}

Received February 19, 2014; Accepted April 24, 2015

DOI: $10.3892 / \mathrm{mmr} .2015 .4282$

\begin{abstract}
Several biological properties of icariin have been identified, including its anticancer effect. However, the potential mechanisms underlying the effect of icariin on HepG2 hepatocellular carcinoma cells remain to be elucidated. The aim of the present study was to examine the effects of icariin on the proliferation and cytoskeleton of HepG2 cells. A 3-(4,5-dimethylthiazol-2-yl)-2,5 diphenyltetrazolium bromide assay was used to assess the antiproliferative effects of icariin and to determine the optimal concentration and treatment schedule of icariin on the HepG 2 cells. Cell cycle analysis was performed using fluorescence activated cell sorting, the protein expression of B-cell lymphoma (Bcl)-2 was determined using immunohistochemical and western blot analyses, and F-actin in the cells was examined using confocal microscopy. The chemotherapeutic drug, oxaliplatin, was used as a positive control. The results demonstrated that the optimal concentration of icarrin to produce an antiproliferative effect on HepG2 cells was $10^{-5} \mathrm{~mol} / \mathrm{l}$, and the optimal treatment duration was $72 \mathrm{~h}$. The icariin group had a significantly higher proportion of cells in the $G_{0} / G_{1}$ phase, compared with the control group, treated with high glucose Dulbecco's modified Eagles medium with $10 \%$ fetal bovine serum $(\mathrm{P}<0.05)$. The proportion of HepG2 cells in the $\mathrm{S}$ phase was significantly lower in the oxaliplatin $(24.19 \%$; $\mathrm{P}<0.05)$ and icariin $(21.07 \%$; $\mathrm{P}<0.01)$ groups, compared with the control group (28.62\%). Icariin markedly decreased the expression of $\mathrm{Bcl}-2$, compared with the control $(\mathrm{P}<0.01)$, and disrupted the polymerization of F-actin filaments in the HepG2 cells. Therefore, the present study demonstrated
\end{abstract}

Correspondence to: Professor Yan-Ling Ren, School of Chinese Medical Formulae, College of Basic Medicine, Liaoning University of Traditional Chinese Medicine, 79 East Chong-Shan Road, Shenyang, Liaoning 110847, P.R. China

E-mail: renyanling1963@hotmail.com

"Contributed equally

Key words: icariin, HepG2, proliferation, cytoskeleton that, at an optimum concentration of $10^{-5} \mathrm{~mol} / \mathrm{l}$, icariin inhibited the proliferation of the HepG2 cells, promoted apoptosis by decreasing the expression of $\mathrm{Bcl}-2$, and disrupted the actin cytoskeleton.

\section{Introduction}

Hepatocellular carcinoma (HCC) is the most common type of cancer in Southeast Asia and Southern Africa, and typically originates from hepatitis $\mathrm{B}$ or $\mathrm{C}$ virus-associated liver cirrhosis $(1,2)$. The incidence of HCC in the US and Europe is also increasing $(3,4)$. Chemotherapy is one of the most extensively used forms of anticancer treatment in China at present, alongside surgery and radiotherapy (5), however, due to the toxicity and side effects associated with currently available chemotherapeutic agents, improvements in treatment are required. Traditional Chinese medicines have long been consumed to prevent and treat various types of cancer, and several active compounds of Chinese medicinal herbs have been assessed for their anticancer effects $(6,7)$.

Icariin is a flavonol glycoside, found in Epimedium spp (Fig. 1). A number of biological properties of icariin have been identified, including cardiovascular protection, a therapeutic effect in erectile dysfunction, and bone-strengthening and anti-hepatotoxic activities (8-11). Additionally, icariin increases lymphokine-activated killer cell and natural killer cell activity in patients with cancer (12). Malignancy is a disorder involving an imbalance of cell proliferation, differentiation and apoptosis. A study by Shi et al (13) reported that icariin exerts an antiproliferative effect on HepG2-bearing nude mice. Furthermore, tumor cell invasion and migration are driven by continuous remodeling of the actin cytoskeleton, which also provides cellular structure and polarization (14), and is a potential therapeutic target in tumor cells. Therefore, the present study evaluated the anticancer effects of icariin on HepG2 cells, focusing on its effects on proliferation, apoptosis and the actin cytoskeleton.

\section{Materials and methods}

Antibodies and reagents. Rabbit polyclonal anti-GAPDH immunoglobulin (Ig)G (sc-25778) and rabbit polyclonal 
anti-B-cell lymphoma (Bcl)-2 IgG (sc-492) antibodies, and horseradish peroxidase (HRP)-conjugated goat anti-rabbit (sc-2004) and goat anti-mouse (sc-2055) secondary antibodies were obtained from Santa Cruz Biotechnology, Inc. (Santa Cruz, CA, USA). Icariin (purity $\geq 99.8 \%$ ) was obtained from the National Institutes for Food and Drug Control (Beijing, China). Oxaliplatin (Eloxatin) was purchased from Sanofi-Aventis (Paris, France). RNase A, RNAiso Plus, the first strand cDNA synthesis kit (cat. no. DRR047) and the SYBR green kit for reverse transctiption-polymerase chain reaction (RT-qPCR) were obtained from Takara Biotechnology Co., Ltd (Dalian, China). The 3-(4,5-dimethylthiazol-2-yl)-2,5 diphenyltetrazolium bromide (MTT) and dimethyl sulfoxide (DMSO) were obtained from Sigma-Aldrich (St. Louis, MO, USA). Fetal bovine serum (FBS), high glucose Dulbecco's modified Eagle's medium (DMEM-H), penicillin G, streptomycin, phosphate-buffered saline (PBS), and the 3,3'-diaminobenzidine (DAB) HRP Color Development kit were obtained from Thermo Fisher Scientific (Waltham, MA, USA). Washes consisted of three 5 min rinses in PBS, unless otherwise specified.

Cell culture. Human HepG2 cells were cultured in DMEM-H supplemented with $10 \%$ FBS, penicillin G (100 U/ml) and streptomycin $(100 \mu \mathrm{g} / \mathrm{ml})$ in a humidified atmosphere with 5\% $\mathrm{CO}_{2}$ and $95 \%$ air at $37^{\circ} \mathrm{C}$. When the cells reached $80 \%$ confluence, after 3 days of culture, they were passaged. The adherent cells were washed and detached using $1 \mathrm{ml} 0.25 \%$ trypsin-EDTA solution for $2 \mathrm{~min}$. The resuspended cells were then placed into three cell culture flasks for incubation under the same conditions.

Cell proliferation. The effect of icariin on HepG2 cell proliferation was determined using an MTT assay. Briefly, the HepG2 cells were seeded in 96-well plates at a density of $1 \times 10^{5}$ cells per well. After $24 \mathrm{~h}$ incubation to allow attachment, the medium was replaced with icariin at various concentrations $\left(10^{-4}, 10^{-5}, 10^{-6}, 10^{-7}\right.$ or $\left.10^{-8} \mathrm{~mol} / \mathrm{l}\right)$ for periods of 24,48 and $72 \mathrm{~h}$. Subsequently, $10 \mu \mathrm{l}$ MTT ( $5 \mathrm{mg} / \mathrm{ml}$ ) was added to each well and the the plates were incubated at $37^{\circ} \mathrm{C}$ for an additional $4 \mathrm{~h}$. The resulting formazan crystals were solubilized by adding $100 \mu \mathrm{l}$ DMSO to each well for $20 \mathrm{~min}$. When the crystals had fully dissolved, the plates were read on a micro-plate reader (iMark; Bio-Rad Laboratories Inc., Hercules, CA, USA) at a wavelength of $490 \mathrm{~nm}$. The concentration of drug required to inhibit $50 \%$ of cell growth $\left(\mathrm{IC}_{50}\right)$ was calculated.

Cell cycle analysis. Once the optimal conditions of icariin treatment of HepG2 cells had been established $\left(10^{-5} \mathrm{M}\right.$ for $72 \mathrm{~h}$ ), cell cycle analysis was performed on the three flasks of cells cultured with either $10 \%$ FBS, oxaliplatin $(10 \mathrm{mg} / \mathrm{l})$, or icariin $\left(10^{-5} \mathrm{~mol} / \mathrm{l}\right)$ for $72 \mathrm{~h}$. The cells were digested using trypsin-EDTA solution, and the resuspended cells were counted $\left(1 \times 10^{6}\right.$ per flask). The cells were fixed with $70 \%$ ethanol at $-20^{\circ} \mathrm{C}$ overnight, washed twice with PBS and incubated with RNaseA $(100 \mathrm{mg} / \mathrm{ml})$ in PBS at room temperature for $30 \mathrm{~min}$. The DNA was labeled in the dark using propidium iodide $(50 \mathrm{mg} / \mathrm{ml})$ and then washed, following which the cells were analyzed using a FACScalibur flow cytometer (BD Biosciences, San Diego, CA, USA).<smiles>COc1ccc(-c2oc3c(CC=C(C)C)c(OC4O[C@H](CO)[C@@H](O)[C@H](O)[C@H]4O)cc(O)c3c(=O)c2OC2O[C@H](C)[C@@H](O)[C@H](O)[C@H]2O)cc1</smiles>

Figure 1. Structural formula of icariin.

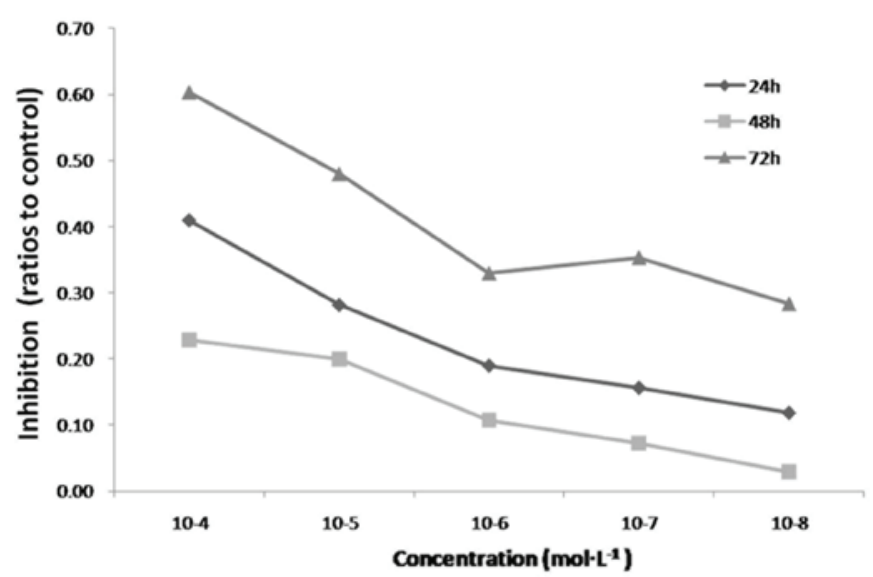

Figure 2. Effect of different concentrations of icariin on the proliferation of human HepG2 cells using a 3-(4,5-dimethylthiazol-2-yl)-2,5 diphenyltetrazolium bromide assay. The concentration of drug required to inhibit $50 \%$ of cell growth was $\sim 10^{-5} \mathrm{~mol} / 1$ at $72 \mathrm{~h}$. The results are expressed as a percentage relative to the control cell number $(\mathrm{n}=10)$.

Immunocytochemistry. The HepG2 cells were cultured in 12 -well plates at a density of $1 \times 10^{4}$ cells/well. FBS (10\%), oxaliplatin $(10 \mathrm{mg} / \mathrm{l})$, or icariin $\left(10^{-5} \mathrm{~mol} / \mathrm{l}^{-1}\right)$ were added for $72 \mathrm{~h}$, following which the plates were washed and the cells were fixed with $95 \%$ ethanol for $15 \mathrm{~min}$. The cells were then washed again, and incubated in blocking buffer for $15 \mathrm{~min}$ at $37^{\circ} \mathrm{C}$ to prevent non-specific antibody binding. The cells were then incubated in anti-Bcl-2 antibody (1:500) for $1 \mathrm{~h}$ at $37^{\circ} \mathrm{C}$, and in secondary antibody $(1: 2,000)$ for $20 \mathrm{~min}$ at room temperature, prior to a final washing step. Staining was visualized using $\mathrm{DAB}$, and nuclei were counterstained with hematoxylin.

Western blot analysis. The cells were seeded in a $2.5 \mathrm{~cm}^{2}$ culture flask. After $24 \mathrm{~h}$, the cells were incubated with FBS (10\%), oxaliplatin $(10 \mathrm{mg} / \mathrm{l})$ or icariin $\left(10^{-5} \mathrm{~mol} / \mathrm{l}^{-1}\right)$. After 3 days, the cells were washed with ice-cold PBS and subsequently lysed using a mammalian tissue protein extraction kit (RIPA Lysis Buffer kit; Boster Biological Technology Co. Ltd., Wuhan, China) containing $1 \mathrm{mM}$ phenylmethanesulfonyl fluoride protease inhibitor. The cells were centrifuged at $12,000 \mathrm{x}$ g for $10 \mathrm{~min}$ at $4^{\circ} \mathrm{C}$, and the supernatants were collected. The protein concentration was determined using a bicinchoninic acid kit (Ding Guo, Beijing, China). Equal quantities $(50 \mu \mathrm{g})$ of protein in the cell extracts were separated on denatured $12 \%$ sodium 
A

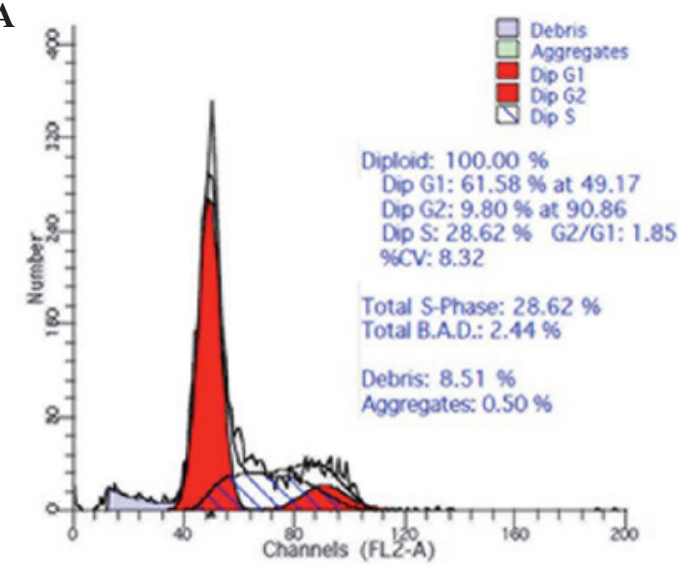

C

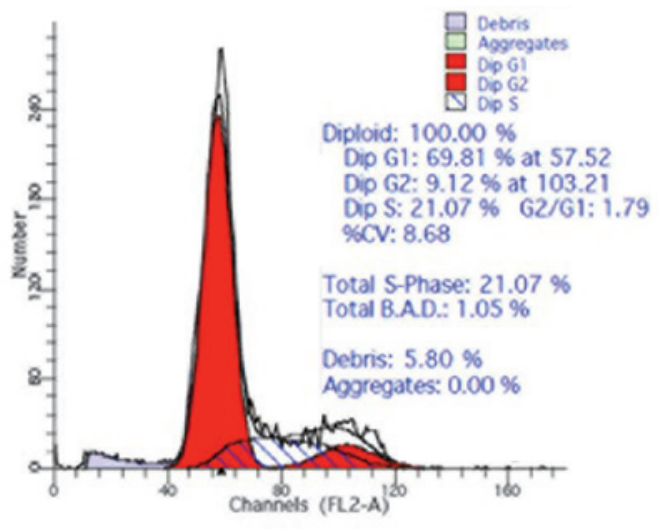

B

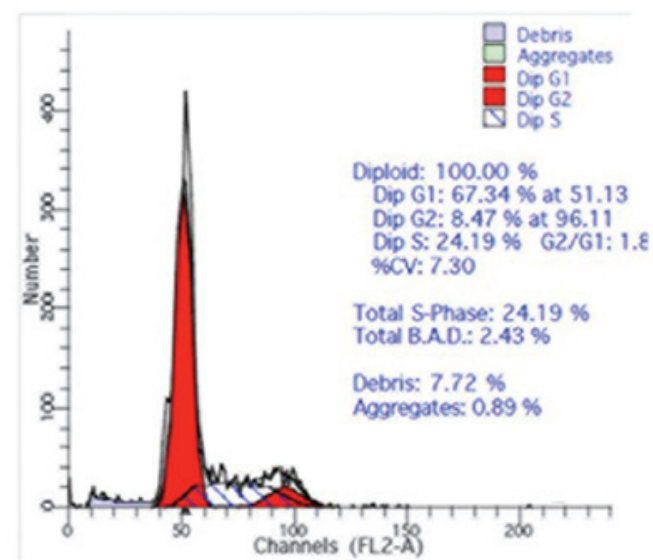

D

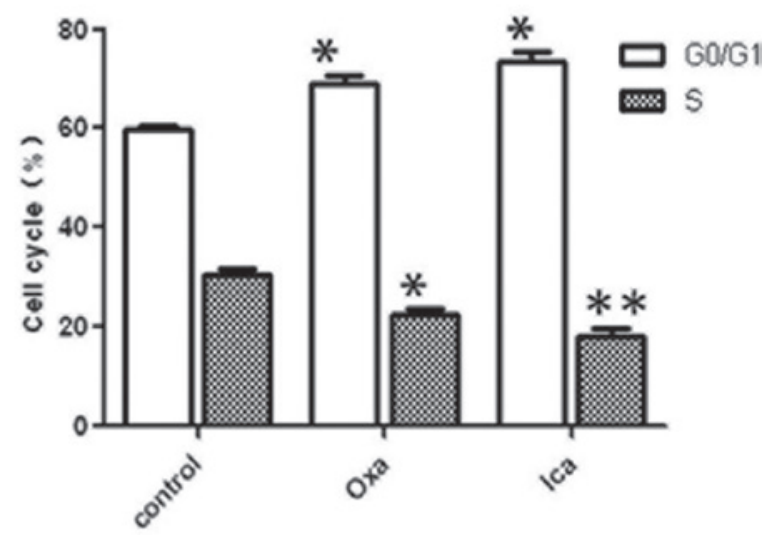

Figure 3. Effect of icariin on the cell cycle in human HepG2 cells. (A) Control; (B) oxaliplatin; (C) icariin. (D) Quantification of the percentage of cells in the $\mathrm{G}_{0} / \mathrm{G}_{1}$ and $\mathrm{S}$ phases. Data are expressed as the mean \pm standard error of the mean. $\mathrm{P}<0.05$ and ${ }^{* *} \mathrm{P}<0.01$, vs control ( $\mathrm{n}=3$ ). Oxa, oxaliplatin; Ica, icariin.

dodecyl sulfate-polyacrylamide gel electrophoresis gels (Ding Guo) and the proteins were transferred onto polyvinylidene difluoride membranes (Immobilon; EMD Millipore, Danvers, MA, USA). The membranes were blocked in blocking buffer [5\% (w/v) non-fat dry milk (Yi Li, Inner Mongolia, China) in Tris-buffered saline containing 0.1\% Tween20 (Boster, Wuhan, China) (TBST)] at $37^{\circ} \mathrm{C}$ for $60 \mathrm{~min}$ and then incubated with anti-Bcl-2 (1:800) or anti-GAPDH antibody $(1: 1,000)$ overnight at $4^{\circ} \mathrm{C}$. Following four washes with TBST, the membranes were incubated with HRP-conjugated secondary antibody $(1: 2,000$; Protein Tech Group, Inc, Chicago, USA) for $1 \mathrm{~h}$ at $37^{\circ} \mathrm{C}$. The membranes were then washed five times with TBST. Finally, the immunoblot signals were visualized using enhanced chemiluminescence reagent (TransGen, Beijing, China). Quantification of proteins was performed using an EC3 Chemi HR 410 imaging system (UVP, Inc., Cambridge, UK).

Confocal microscopic analysis of F-actin. The cells were incubated in confocal plates at a density of $1 \times 10^{3}$ cells per plate. After 3 days, the cells were washed and fixed with 95\% ethanol for $15 \mathrm{~min}$, followed by another wash. For imaging analysis of the F-actin filaments, the HepG2 cells were stained with phalloidin-fluorescein isothiocyanate (FITC; 50 mg/l; Invitrogen Life Technologies, Carlsbad, CA, USA) in the dark for $20 \mathrm{~min}$, prior to three washes in PBS. Finally, the samples were analyzed using a confocal laser scanning microscope (Model FV500; Olympus, Tokyo,
Japan). Images were captured and quantified using FluoView software (Olympus).

Statistical analysis. One-way analysis of variance followed by Tukey's post-hoc comparison was used to compare groups. All data are expressed as the mean \pm standard error of the mean. $\mathrm{P}<0.05$ was considered to indicate a statistically significant difference. Each experiment was repeated at least three times.

\section{Results}

Icariin inhibits Hep 2 cell proliferation. The antiproliferative property of icariin in cultured HepG2 cells was determined using an MTT assay. Icariin significantly inhibited the proliferation of the HepG2 cells at concentrations between $10^{-4}$ and $10^{-8} \mathrm{~mol} / \mathrm{l}$ (Fig. 2). The $\mathrm{IC}_{50}$ was observed at $\sim 10^{-5} \mathrm{~mol} / 1$ at $72 \mathrm{~h}$, therefore, this concentration was selected for use in the subsequent experiments.

Icariin arrests HepG 2 cell cycle at the $G_{0} / G_{1}$ phase. The oxaliplatin group and the icariin group exhibited significantly higher proportions of the cell population in the $G_{0} / G_{1}$ phase, compared with the control group $(\mathrm{P}<0.05$; Fig. 3$)$. The proportion of HepG2 cells in the oxaliplatin $(24.19 \%)$ and icariin $(21.07 \%)$ groups at the $\mathrm{S}$ phase were significantly lower, compared with that in the control group $(28.62 \%$; $\mathrm{P}<0.05$ and 

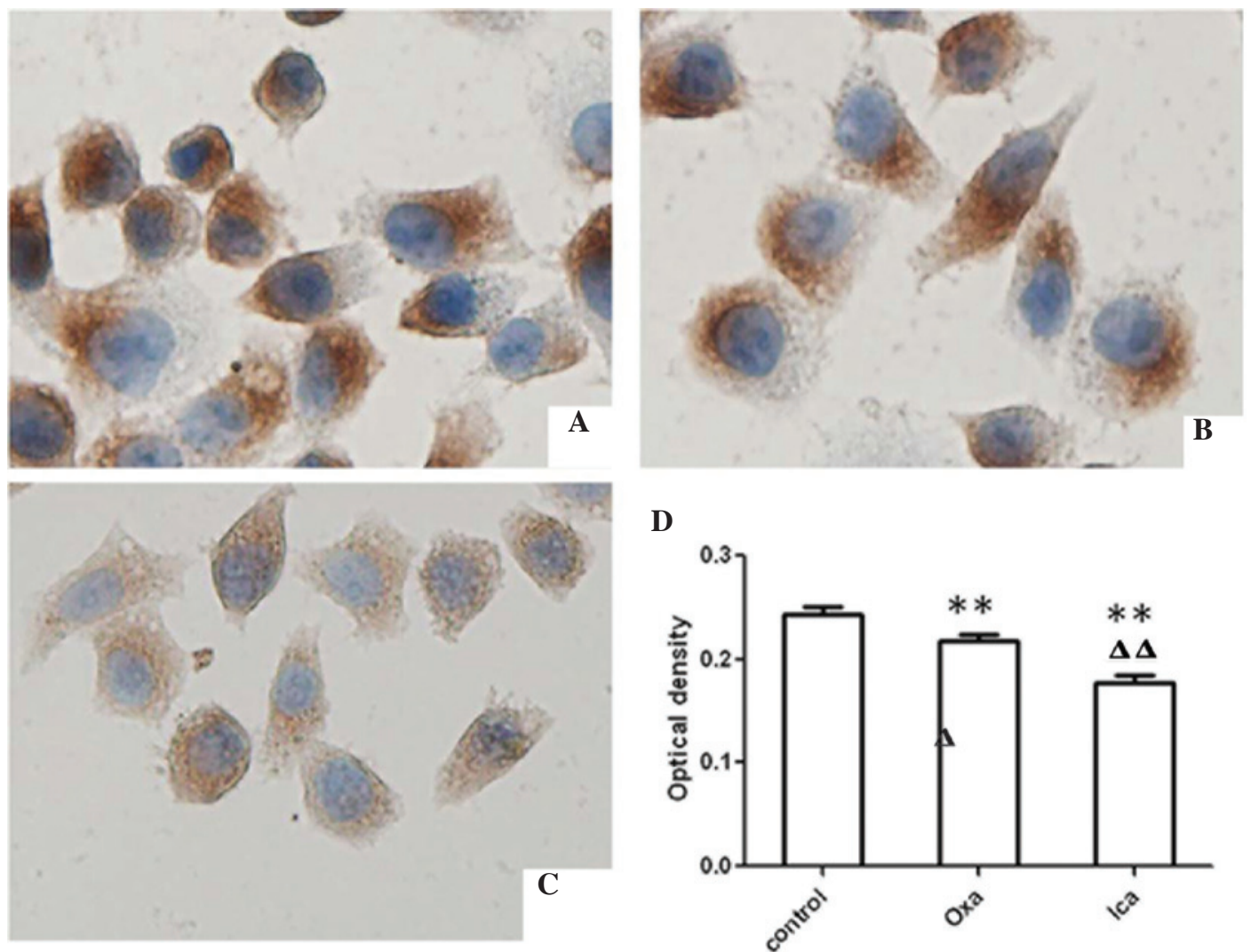

Figure 4. Bcl-2 immunoreactivity in human HepG2 cells. (A) control group; (B) oxaliplatin; (C) icariin (magnification, x200). (D) Optical density analysis. Data are expressed as the mean \pm standard error of the mean. ${ }^{*} \mathrm{P}<0.05$ and ${ }^{* *} \mathrm{P}<0.01$, vs control; ${ }^{\Delta \Delta} \mathrm{P}<0.01$, vs oxaliplatin ( $\mathrm{n}=3$ ). Oxa, oxaliplatin; Ica, icariin.
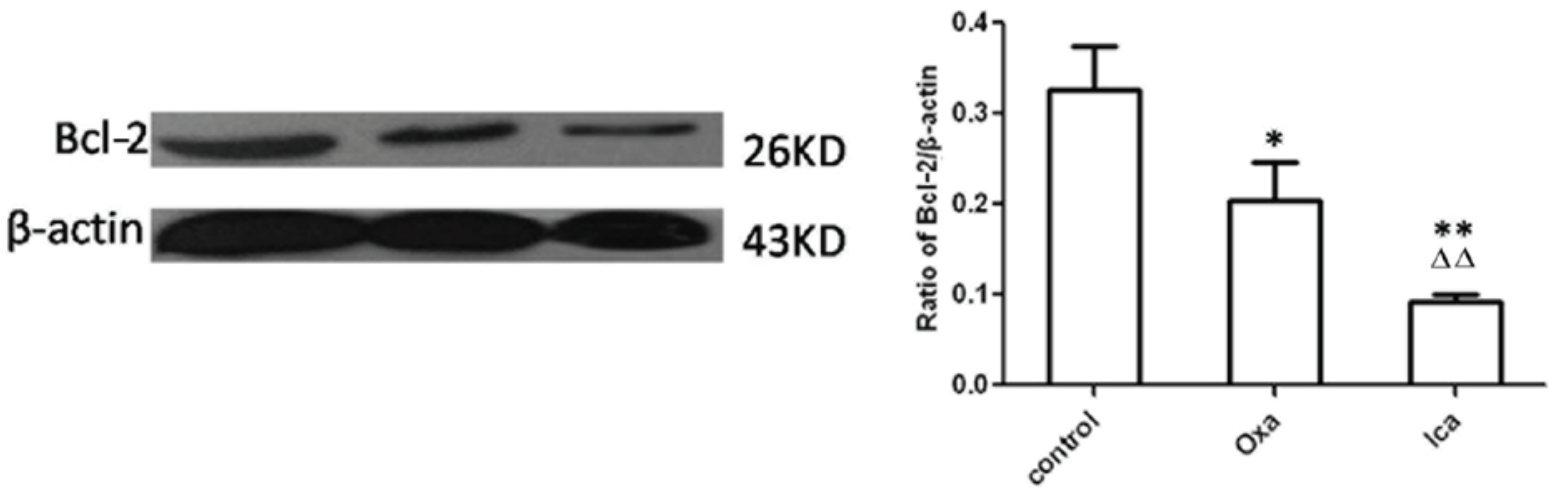

Figure 5. Western blot analysis of the protein expression of Bcl-2 in human HepG2 cells. Data are expressed as the mean \pm standard error of the mean. ${ }^{*} \mathrm{P}<0.05$ and ${ }^{* *} \mathrm{P}<0.01$, vs control; ${ }^{4} \mathrm{P}<0.05$, vs oxaliplatin. (n=3). Bcl-2, B-cell lymphoma 2; Oxa, oxaliplatin; Ica, icariin.
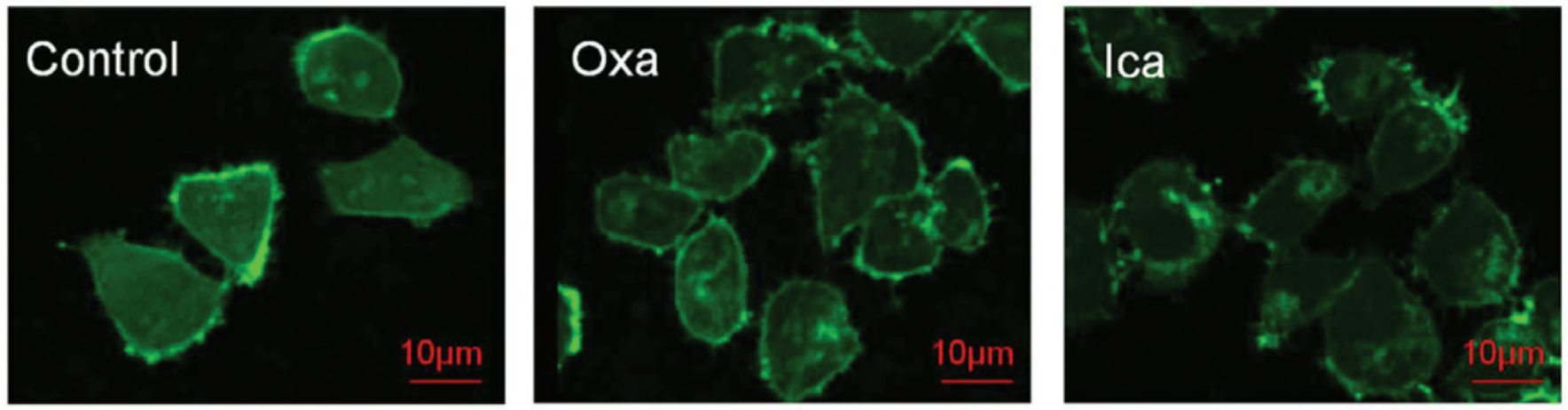

Figure 6. Confocal microscopic images revealing the disruption of F-actin cytoskeleton polymerization by icariin and oxaliplatin in human HepG2 cells. Oxa, oxaliplatin; Ica, icariin. 
$\mathrm{P}<0.01$, respectively). No significant difference in cell cycle distribution was observed between the oxaliplatin and icariin groups.

Icariin inhibits the expression of $\mathrm{Bcl}-2$. Bcl-2, an anti-apoptotic molecule, can be used as a marker for cell apoptosis. Therefore, the presents study examined expression of $\mathrm{Bcl}-2$ in HepG2 cells using immunocytochemical and western blot analyses. The expression levels of Bcl-2 were significantly lower in the oxaliplatin and icariin groups, compared with the control group ( $\mathrm{P}<0.01$; Fig. 4). Furthermore, the expression of Bcl-2 in the icariin-treated cells was lower than that in the oxaliplatin-treated cells $(\mathrm{P}<0.01)$. Western blot analysis confirmed the results of the immunohistochemical analysis, with a lower expression level of $\mathrm{Bcl}-2$ observed in the oxaliplatin and icariin groups, compared with the control $(\mathrm{P}<0.05$ and $\mathrm{P}<0.01$, respectively; Fig. 5). Icariin treatment led to a sharp decrease in the protein expression of $\mathrm{Bcl}-2$, compared with oxaliplatin treatment $(\mathrm{P}<0.01)$.

Disruption of F-actin by icariin. Confocal microscopy was used to determine the effects of icariin on F-actin in the HepG2 cells (Fig. 6). In the untreated HepG2 cell control group, long-form and regular F-actin filaments were observed, however, polymerization of F-actin filaments was noticeably disrupted following 3 days of exposure to either oxaliplatin or icariin.

\section{Discussion}

Icariin, the major component of Herba epimedii, is reported to exhibit several biological activities with no clear side effects (15). The results of the present study demonstrated that, in human HepG2 cells, icariin inhibited the proliferation, affected the cell cycle and cell apoptosis, and disrupted the F-actin cytoskeleton.

Previous studies have investigated the antiproliferative efficacy of icariin on HepG2 cells and the possible underlying mechanism $(13,16)$. It is well known that DNA damage can induce $G_{1}$ phase arrest. Previous studies have demonstrated that cell cycle arrest at the $\mathrm{G}_{0} / \mathrm{G}_{1}$ phase can inhibit the proliferation of HepG2 cells $(17,18)$. In the present study, exposure to icariin $\left(10^{-5} \mathrm{~mol} / \mathrm{l}\right.$ for $\left.72 \mathrm{~h}\right)$ significantly increased the proportion of cells in the $G_{0} / G_{1}$ phase and decreased the proportion of cells in the $\mathrm{S}$ phase, indicating that icariin inhibited proliferation and prevented the cells from entering the $\mathrm{S}$ phase.

Apoptosis is regulated by two major pathways: The death receptor-induced extrinsic pathway and the mitochondria-apoptosome-mediated intrinsic pathway (19). Bcl-2 family proteins are central in controlling the mitochondrial pathway, and $>20$ members of this family have been identified, including Bcl-2, which is one of the proteins that suppresses apoptosis (20). The overexpression of $\mathrm{Bcl}-2$ causes HepG 2 cells to become resistant to the induction of apoptosis, possibly by preventing the release of cytochrome $c$ (21). In the present study, icariin significantly decreased the protein expression of Bcl-2, indicating that it may promote the apoptosis of HepG2 cells by suppressing the protein expression of Bcl-2.

The cytoskeleton is the internal framework of a cell and is largely composed of actin microfilaments, in addition to microtubules and intermediate filaments. Actin is important in the maintenance of cell pattern and tight junctions between cells (22-24). The balance between microfilament dissociation and polymerization regulates the movement, adhesion and fission of cells $(25,26)$. F-actin has been used as a sensitive index in the assessment of the development of tumor cells in certain types of early phase cancer (27-29). In the present study, treatment of the HepG2 cells with icariin significantly decreased polymerization of the F-actin cytoskeletons. Thus, it is possible that icariin suppresses the development of HepG2 cells by acting on the microfilament, and it is suggested that F-actin may be important in HepG2 cells.

In conclusion, the present study demonstrated that, at an optimal concentration of $10^{-5} \mathrm{~mol} / \mathrm{l}$, icariin inhibited the proliferation of HepG2 cells, promoted their apoptosis by enhancing the protein expression of Bcl-2 and, importantly, suppressed polymerization of the F-actin cytoskeleton in the HepG2 cells. Therefore, icariin offers promise as a novel therapeutic agent in the treatment of HCC.

\section{Acknowledgements}

The study was supported by the Science Foundation of Liaoning University of Traditional Chinese Medicine (grant no 81373527 )and the Key Laboratory of Ministry of Education for Traditional Chinese Medicine Viscera-State Theory and Applications.

\section{References}

1. Adams JM and Cory S: The Bcl-2 protein family: Arbiters of cell survival. Science 281: 1322-1326, 1998.

2. Bell RM: A review of complementary and alternative medicine practices among cancer survivors. Clin J Oncol Nurs 14: 365-370, 2010.

3. Chang HC, Chen TL and Chen RM: Cytoskeleton interruption in human hepatoma HepG2 cells induced by ketamine occurs possibly through suppression of calcium mobilization and mitochondrial function. Drug Metab Dispos 37: 24-31, 2009.

4. Colombo E, Marine J-C, Danovi D, Falini B and Pelicci PG: Nucleophosmin regulates the stability and transcriptional activity of p53. Nat Cell Biol 4: 529-533, 2002.

5. Hall A: Rho GTPases and the actin cytoskeleton. Science 279: 509-514, 1998.

6. He W, Sun H, Yang B, Zhang D and Kabelitz D: Immunoregulatory effects of the herba Epimediia glycoside icariin. Arzneimittelforschung 45: 910-913, 1995.

7. Huo X, Xu XJ, Chen YW, Yang HW and Piao ZX: Filamentous-actins in human hepatocarcinoma cells with CLSM. World J Gastroenterol 10: 1666-1668, 2004.

8. Kluck RM, Bossy-Wetzel E, Green DR and Newmeyer DD: The release of cytochrome $\mathrm{c}$ from mitochondria: A primary site for Bcl-2 regulation of apoptosis. Science 275: 1132-1136, 1997.

9. Lau WY and Lai EC: Hepatocellular carcinoma: Current management and recent advances. Hepatobiliary Pancreat Dis Int 7: 237-257, 2008

10. Liu WJ, Xin ZC, Xin H, Yuan YM, Tian L and Guo YL: Effects of icariin on erectile function and expression of nitric oxide synthase isoforms in castrated rats. Asian J Androl 7: 381-388, 2005.

11. Fiume L, Manerba M, Vettraino M and Di Stefano G: Effect of sorafenib on the energy metabolism of hepatocellular carcinoma cells. Eur J Pharmacol 670: 39-43, 2011.

12. Okuda K: Hepatocellular carcinoma: Recent progress. Hepatology 15: 948-963, 1992.

13. Shi MD, Liao YC, Shih YW and Tsai LY: Nobiletin attenuates metastasis via both ERK and PI3K/Akt pathways in HGF-treated liver cancer HepG2 cells. Phytomedicine 20: 743-752, 2013.

14. Shumilina EV, Negulyaev YA, Morachevskaya EA, Hinssen H and Khaitlina SY: Regulation of sodium channel activity by capping of actin filaments. Mol Biol Cell 14: 1709-1716, 2003. 
15. Sun L, Chen W, Qu L, Wu J and Si J: Icaritin reverses multidrug resistance of HepG2/ADR human hepatoma cells via downregulation of MDR1 and P-glycoprotein expression. Mol Med Rep 8: $1883-1887,2013$

16. Tong JS, Zhang QH, Huang X, et al: Icaritin causes sustained ERK1/2 activation and induces apoptosis in human endometrial cancer cells. PLoS One 6: e16781, 2011.

17. Zhang XH,Zou ZQ, Xu CW, Shen YZ and Li D: Myricetin induces G2/M phase arrest in HepG2 cells by inhibiting the activity of the cyclin B/Cdc2 complex. Mol Med Rep 4: 273-277, 2011.

18. Tan W, Lu J, Huang M, Li Y, Chen M, Wu G, Gong J, Zhong Z, $\mathrm{Xu} \mathrm{Z}$, Dang Y, et al: Anti-cancer natural products isolated from chinese medicinal herbs. Chin Med 6: 27, 2011.

19. Wang QQ, Zhang ZY, Xiao JY, Yi C, Li LZ, Huang Y and Yun JP: Knockdown of nucleophosmin induces $S$-phase arrest in HepG2 cells. Chin J Cancer 30: 853-860, 2011.

20. Wang Y, Dong H, Zhu M, Ou Y, Zhang J, Luo H, Luo R, Wu J, Mao $\mathrm{M}$, Liu X, et al: Icariin exterts negative effects on human gastric cancer cell invasion and migration by vasodilator-stimulated phosphoprotein via Rac1 pathway. Eur J Pharmacol 635: 40-48, 2010.

21. $\mathrm{Hu} \mathrm{W}$ and Kavanagh JJ: Anticancer therapy targeting the apoptotic pathway. Lancet Oncol 4: 721-729, 2008.

22. Williams JI, Weitman S, Gonzalez CM, Jundt CH, Marty J, Stringer SD, Holroyd KJ, Mclane MP, Chen Q, Zasloff M and Von Hoff DD: Squalamine treatment of human tumors in nu/nu mice enhances platinum-based chemotherapies. Clin Cancer Res 7: 724-733, 2001.
23. Skillman KM, Diraviyam K, Khan A, et al: Evolutionarily divergent, unstable filamentous actin is essential for gliding motility in apicomplexan parasites. PLoS Pathog 7: e1002280, 2011.

24. Ozyamak E, Kollman JM and Komeili A: Bacterial actins and their diversity. Biochemistry 52: 6928-6939, 2015.

25. Xu HB and Huang ZQ: Icariin enhances endothelial nitric-oxide synthase expression on human endothelial cells in vitro. Vascul Pharmacol 47: 18-24, 2007.

26. Yan MX, Yang J, Sun Q, Liu CH, Wang YG and Wang WQ: Hepatocellular carcinoma that arose from primary Sjögren's syndrome. Ann Hepatol 12: 824-829, 2013.

27. Yang JX, Fichtner I, Becker M, Lemm M and Wang XM: Anti-proliferative efficacy of icariin on HepG2 hepatoma and its possible mechanism of action. Am J Chin Med 37: 1153-1165, 2009.

28. Yang YL: Polymerization of actins. Biology (Basel) 18: 13-14, 1995.

29. Zhang DW, Cheng Y, Wang NL, Zhang JC, Yang MS and Yao XS: Effects of total flavonoids and flavonol glycosides from Epimedium koreanum Nakai on the proliferation and differentiation of primary osteoblasts. Phytomedicine 15: 55-61, 2008. 